\title{
A QUESTÃO DA FUNDAMENTAÇÃO DOS DIREITOS HUMANOS SOB O PRISMA AXIOLÓGICO
}

\author{
Bruna Martins Amorim Dutra*
}

\begin{abstract}
RESUMO
O presente artigo objetiva analisar a questão da fundamentação dos direitos humanos a partir de uma ótica filosófica. Desta feita, busca-se demonstrar que a adoção de uma teoria axiológica relativista ou universalista possui necessárias implicações na orientação esposada a respeito dos fundamentos dos direitos do homem, culminando nas teorias negativistas e fundamentadoras dos direitos humanos.
\end{abstract}

PALAVRAS-CHAVE: Direitos humanos; Fundamentação; Teorias axiológicas.

\begin{abstract}
This article aims to examine the question of the foundations of human rights from a philosophical perspective. Thus, it is shown that the adoption of a universalist or relativist axiological theory has necessary implications on the guidance espoused concerning the grounds of human rights, culminating in the naysayers and fundamental theories of human rights.
\end{abstract}

KEYWORDS: Human rights; Foundation; Axiological theories.

\section{INTRODUÇÃO}

A sociedade globalizada contemporânea é marcada por abruptos e reiterados processos de transformação. O ritmo acelerado que seguem as recentes mudanças tem conduzido ao primado de um relativismo axiológico. Assim, tudo vem, cada vez mais, se tornando discutível, efêmero, relativo.

Nesse contexto de crise de fundamentos, ganha enorme relevo a questão da fundamentação dos direitos humanos, em especial no tocante à indagação sobre o seu caráter absoluto ou relativo. No presente artigo, a temática será abordada sob a ótica filosófica, notadamente à vista das teorias axiológicas existentes.

Conforme restará demonstrado, ambos os assutos estão vinculados por uma íntima relação, possuindo o posicionamento adotado na órbita valorativa fortes implicações na seara da fundamentação dos direitos do homem. Genericamente, é possível vislumbrar duas orientações principais para as referidas questões, quais sejam, o relativismo e o universalismo.

Portanto, no capítulo que se segue, serão abordadas as teorias axiológicas que ostentam maior destaque. Posteriormente, à luz das idéias valorativas expostas, será

\footnotetext{
* Mestranda em Direito Penal pela Universidade do Estado do Rio de Janeiro (UERJ). Pesquisadora pela Fundação Carlos Chagas Filho de Amparo à Pesquisa do Estado do Rio de Janeiro (FAPERJ). Graduação em Direito pela UERJ.
} 
enfrentada a tormentosa questão da fundamentação dos direitos humanos, tão debatida na efêmera conjuntura atual.

\section{TEORIAS AXIOLÓGICAS}

As investigações sobre a idéia de valor remontam à época da Antiguidade. Todavia, o surgimento de uma teoria axiológica autônoma como objeto de estudo da Filosofia apenas ocorreu a partir do século XX, notadamente com as obras de Lapie, Hartmann e Urban ${ }^{1}$.

As variadas divergências existentes entre os filósofos em torno da questão dos valores ensejaram o aparecimento de diferentes teorias axiológicas. Verifica-se, porém, que o ponto central distintivo das referidas teorias reside no embate entre as idéias de relativismo historicista e de universalismo. Com efeito, conforme expõe Reale ${ }^{2}$, prevaleceu, inicialmente, o entendimento de que não haveria valores absolutos, estando a axiologia sujeita à Psicologia ou à Sociologia. Contudo, em especial a partir das atrocidades cometidas durante a $1^{\mathrm{a}}$ Guerra Mundial, adquiriu importância o tema das invariantes axiológicas, havendo, atualmente, diversos posicionamentos sobre a questão.

A seguir, serão abordadas, de modo sucinto, as principais teorias axiológicas existentes, sob a ótica do relativismo e do universalismo. Consoante restará evidenciado, tais construções teóricas possuem importantes implicações na questão da fundamentação dos direitos humanos, notadamente com relação à temática da existência ou não de um conteúdo essencial invariável desses direitos.

\subsection{Relativismo}

Não obstante existam discordâncias ${ }^{3}$, Nietzsche é, geralmente, identificado como o precursor do relativismo, vez que afirmava que a realidade seria dinâmica, regida pela "vontade de poder", de modo a inexistir uma organização pré-estabelecida. O caos e o acaso estariam sempre operantes na realidade, prevalecendo o mais forte. $\mathrm{Na}$ ótica de Nietzsche, as coisas não ostentariam existência em si, mas sempre se subordinariam às relações de poder que possuíssem.

\footnotetext{
${ }^{1}$ REALE, Miguel. Paradigmas da cultura contemporânea. $1^{\text {a }}$ ed. $2^{\text {a }}$ tir. São Paulo: Saraiva, 1999, p. 103.

${ }^{2}$ Ibid. p. 103-107.

${ }^{3}$ P. ex., ROCHA, Silvia Pimenta Velloso. O relativismo como niilismo, ou os sem teto da metafísica. Revista Trágica: estudos sobre Nietzsche, $2^{\circ}$ semestre de 2008, vol. 1, n 2, p. 161-169, para quem "o perspectivismo, longe de constituir um relativismo, é um "relacionalismo" ou uma ontologia das relações, ao passo que o relativismo propriamente dito permanece uma posição metafísica que se desconhece enquanto tal" (p. 162).
} 
A partir das idéias nietzschianas, prevaleceu, de início, no estudo dos valores, a visão relativista, a qual desconsidera que haja quaisquer valores absolutos. Dessa forma, a Axiologia ora se encontrava sujeita à Psicologia, quando teria por base a consciência individual, ora estava subordinada à Sociologia, fulcrando-se na consciência coletiva.

O relativismo assumiu, com o decorrer do tempo, ainda diversas outras roupagens, permanecendo, porém, em todas elas, sempre a idéia central da inexistência de valores universais e atemporais. Conforme explana Reale, "de certa forma, com Marcuse e outros, o que se pretendeu foi a negação radical de qualquer invariante axiológica, ficando o homem anarquicamente entregue à sua ilimitada liberdade, nada lhe sendo proibido"4 .

Cabe destacar, por oportuno, que o século XIX consistiu num ambiente especialmente fértil para o desenvolvimento do relativismo. Tal fato teve como causa crucial o advento do positivismo, o qual ensejou a consagração do método empírico de descoberta e o surgimento da falaciosa idéia de progresso ilimitado da humanidade em virtude do avanço da ciência. Com efeito, o naturalismo propugnava o direcionamento do conhecimento tão-somente àquilo que fosse passível de explicação, além do que o tecnicismo que despontava suprimiu a importância até então conferida à atividade espiritual. Todavia, consoante constata Hannah Arendt, “o progresso, por certo, é um dos artigos mais sérios e complexos encontrados no mercado de superstições de nosso tempo"

Registre-se que o pensamento relativista encontra força até os dias de hoje, haja vista a atual crise de fundamentos que enfrenta a Modernidade. Notadamente com o historicismo, que destaca a perene mutabilidade das condições históricas, e com o incontestável fato do multiculturalismo, mostra-se revigorada a idéia da inviabilidade de se alcançar uma visão universal e definitiva da realidade, e, portanto, da inexistência de valores absolutos a serem erigidos como fundamentos. Diante disso, nota a professora Silvia Rocha que "o relativismo pretende assim realizar uma operação impossível: denunciar a ausência de fundamentos permanecendo ele próprio numa posição fundada" ${ }^{\text {. }}$

\subsection{Universalismo}

\footnotetext{
${ }^{4}$ REALE, Miguel. Op. cit. p. 104.

${ }^{5}$ ARENDT, Hanna. Sobre a violência. Tradução de André Duarte. $3^{\mathrm{a}}$ ed. Rio de Janeiro: Relume Dumará, 2001 , p. 29.

${ }^{6}$ ROCHA, Silvia Pimenta Velloso. Op. cit. p. 164.
} 
Os contornos da idéia de universalismo axiológico podem ser visualizados já em Immanuel Kant, quando da elaboração do conceito de imperativo categórico. A partir da premissa de que haveria um antagonismo entre a sensibilidade e a razão, Kant erigiu a vontade livre de inclinações individuais - boa vontade - como guia determinante da moralidade, de modo que pudesse ser observada por todo ser racional. Considerando que a sensibilidade comportaria uma multiplicidade de anseios consoante as condições pessoais dos indivíduos, não permitindo a obtenção de uma lei moral universal, tal desiderato deveria ser alcançado através da razão prática. Então, uma máxima seria moral quando tivesse o condão de ser universalizada, vinculando-se à noção de dever como imperativo categórico.

Muitos autores seguiram a direção universalista da metafísica kantiana, notadamente sob o viés de um idealismo subjetivista. Nesse contexto, Jorge Jaime destaca os posicionamentos de Rodolf Lotze, o qual apreendia os valores como entes abstratos originários do pensamento, e da Escola de Baden, que aspirava alcançar valores válidos universalmente na seara do dever-ser ${ }^{7}$.

A visão universalista da axiologia, todavia, emergiu com maior nitidez e vigor a partir da notoriedade das atrocidades cometidas durante a $1^{\text {a }}$ Guerra Mundial, ganhando destaque o tema das invariantes axiológicas e a questão do fundamento. Max Scheler e Nicolai Hartmann, os quais assumiram como ponto de partida as lições fenomenológicas de Husserl, foram os principais responsáveis pela guinada do universalismo na época.

De acordo com o pensamento fenomenológico, os valores são objetos ideais, dotados de autonomia em relação aos objetos reais. Identifica-se entre eles tão-somente uma referibilidade, visto que os valores não são compreendidos pela fenomenologia como uma abstração. Assim, o professor Jorge Câmara explica que a atitude em tela objetiva "o retorno às próprias coisas, ao vivido em detrimento das construções categoriais aprioristícas com que a metafísica kantiana pretendeu reger a constituição de sentidos do mundo" ${ }^{\text {. }}$

Ao contrário dos objetos reais, que são contingentes, os valores, integrando o domínio dos seres ideais, seriam pré-existentes, universais e atemporais. Destarte, não obstante os fenômenos reais estejam sujeitos à mutabilidade, sua essência ou significação seria perene, consubstanciando o valor e, portanto, o fundamento. Nas palavras de Aquiles Guimarães,

\footnotetext{
${ }^{7}$ JAIME, Jorge. Ser e Valor. Vol. 1, $2^{\mathrm{a}}$ ed. Rio de Janeiro, 2003, p. 48-50.

${ }^{8}$ CÂMARA, Jorge Luis Fortes Pinheiro da. Os fundamentos e a crise do direito na modernidade: perspectivas filosóficas dos direitos humanos segundo a fenomenologia. Tese de doutorado em Filosofia na UFRJ, Instituto de Filosofia e Ciências Sociais. Rio de Janeiro, 2007, p. 40.
} 
"essência é aquilo que caracteriza a invariância do objeto; é a idéia universal e necessária sem a qual não temos a evidência da compreensão daquilo de que falamos"9.

Assentadas tais premissas, sustenta a fenomenologia que os valores não seriam evidenciados racionalmente, mas sim pela consciência intencional do homem. Esse processo de apreensão da essência dos fenômenos reais pela intuição emocional se denomina redução eidética. Já a ponderação acerca dos sentidos do domínio dos seres ideais constituiria a redução transcendental.

Reitere-se que, em consonância com o pensamento exposto, o valor corresponde ao fundamento. A partir desse dado, a consciência intencional que o apreende, doando sentido para os objetos, seria, por consequência, o fundamento último dos valores. Nesse contexto, é válido transcrever um trecho das lições do professor Aquiles Guimarães:

\begin{abstract}
somente a intencionalidade constituinte (evidenciadora) poderá fundar os sentidos dos objetos, tornando possível a compreensão da objetividade em geral. A consciência humana é o fundamento do fundamento porque só ela descobre, evidencia e garante todo fundamento. ${ }^{10}$
\end{abstract}

Ainda respeito dos valores, a fenomenologia propugna que esses objetos ideais podem ser positivos ou negativos, remetendo à noção de bem e mal. Ademais, entende-se possível identificar uma escala hierárquica de valores por intermédio dos atos de preferência, os quais também seriam provenientes da intuição emocional.

Por seu turno, Miguel Reale não compreende o valor como um objeto ideal, integrante do reino do ser, mas sim como pertencente ao domínio do dever-ser ${ }^{11}$, distinguindo-se, no ponto, do pensamento fenomenológico. Explica o autor que "o ser do homem é o seu deverser", de modo que aquele consistiria no "valor-fonte de todos os valores"12. A partir desses pressupostos, e considerando que o homem é um ser fundamentalmente histórico, Reale adota um historicismo axiológico. Em suas palavras:

entre a concepção idealista da experiência axiológica como totalidade do processo histórico da Idéia ou do Absoluto e a vertente oposta, a visão empírica do historicismo relativista, é possível uma terceira solução, que resulta de uma compreensão transcendental (em sentido em que Kant e Husserl empregam este adjetivo, bem diverso da Metafísica tomista) do valor em correlação com a experiência histórica. ${ }^{13}$

\footnotetext{
${ }^{9}$ GUIMARÃES, Aquiles Côrtes. Para uma teoria fenomenológica do Direito - I. Cadernos da EMARF, Fenomenologia e Direito. Rio de Janeiro, v. 3, nº 1, abr./set.2010, p. 21.

${ }^{10}$ Id. Edmundo Russerl e o Fundamento Fenomenológico do Direito. Cadernos da EMARF, Fenomenologia e Direito. Rio de Janeiro, v. 2, $\mathrm{n}^{\circ}$ 1, abr./set.2009, p. 76.

${ }^{11}$ REALE, Miguel. Paradigmas da cultura contemporânea. $1^{a}$ ed. $2^{a}$ tir. São Paulo: Saraiva, 1999, p. 105 e 107.

${ }^{12}$ Ibid. p. 105.

${ }^{13}$ Ibid. p. 106.
} 
É importante salientar que o reconhecimento da historicidade do homem por parte de Miguel Reale não conduz, necessariamente, a um pensamento axiológico relativista. Conforme nota Aquiles Guimarães, embora se constate a mutabilidade dos fatos ao longo da história, os valores subsistentes independentemente das modificações ocorridas consubstanciam as invariantes axiológicas ${ }^{14}$. Nesse sentido, o professor ensina que os valores pré-existem e são apreendidos pela consciência intencional do homem, valor-fonte de todos os valores, ensejando os processos históricos tão-somente o reconhecimento dos valores e a atribuição de sentido aos mesmos ${ }^{15}$.

Em suma, percebe-se que a ótica universalista da axiologia também ostenta importantes defensores, embora sob diferentes vieses. $\mathrm{O}$ ponto comum entre eles reside na difícil empreitada de buscar valores absolutos e universais na atual conjuntura de crise de fundamentos em que se encontra imersa a Modernidade.

\section{FUNDAMENTAÇÃO DOS DIREITOS HUMANOS}

Uma vez analisadas as principais teorias axiológicas sob o prisma do relativismo e do universalismo, cumpre tratar, no momento, da também tormentosa questão sobre a fundamentação dos direitos humanos. Conforme evidenciado, dado que o estudo dos valores possui íntima relação com a temática do fundamento, constata-se que a orientação esposada no âmbito da axiologia possuirá implicações na questão da fundamentação dos direitos humanos.

A seguir, serão abordados os dois principais posicionamentos acerca do assunto. Primeiramente, cuidar-se-á das teorias que prescindem do esforço de fundamentar os direitos humanos, seja por considerá-lo destituído de importância, seja por reputar ser essa uma tarefa impossível de realização. Posteriormente, serão analisadas as teorias que intentam construir um arcabouço fundamental em que se estribem os direitos do homem, sob diferentes perspectivas.

\subsection{Teorias negativistas}

\footnotetext{
${ }^{14}$ GUIMARÃES, Aquiles Côrtes. O que é a teoria tridimensional do Direito? Estudos Jurídicos, p. 4.

${ }^{15}$ Id. Direito, valor e técnica. Cadernos da EMARF, Fenomenologia e Direito. Rio de Janeiro, v. 1, nº 2 , out.2008/mar.2009, p. 92-93.
} 
Consoante exposto, parcela da doutrina reputa irrelevante a discussão a respeito dos fundamentos dos direitos humanos, por distintos motivos. A seguir, referidas teorias, aqui denominadas genericamente de negativistas, serão abordadas de modo sucinto, notadamente sob as perspectivas realista e positivista.

\subsubsection{Perspectiva realista}

De acordo com a perspectiva realista, a questão que merece real enfoque não mais é a da justificação dos direitos humanos, mas sim a concernente ao modo de protegê-los efetivamente, deslocando-se a atenção para o plano da eficácia. O principal expoente dessa visão é Noberto Bobbio.

O aludido filósofo defende que a pretensão de se alcançar um fundamento absoluto para os direitos humanos é ilusória, haja vista a indeterminação do termo, o fenômeno do historicismo, a heterogeneidade e a antinomia desses direitos ${ }^{16}$. Segundo Bobbio, malgrado o fundamento dos direitos do homem corresponda aos valores últimos, estes não encontrariam um fundamento. Assim, a respeito dos valores últimos, afirma que "são necessárias concessões de ambas as partes: nessa obra de conciliação, que requer renúncias recíprocas, entram em jogo as preferências pessoais, as opções políticas, as orientações ideológicas"17, o que conduz a um relativismo axiológico.

Em contraposição ao pensamento de Bobbio, ressalte-se que a fenomenologia aduz que o fundamento do fundamento seria a consciência intencional do homem, na qualidade de doadora de sentidos para os objetos através da redução eidética. Assim, caberia ao homem intuir os valores universais pré-existentes no domínio dos seres ideais. Outrossim, a despeito de o historicismo axiológico de Reale reconhecer o homem como ser histórico, ainda assim admite a existência das invariantes axiológicas.

Noberto Bobbio, sem embargo, ao não vislumbrar um fundamento absoluto, baseia os direitos humanos no consenso geral sobre os valores, sempre dotado da característica da mutabilidade. Portanto, em especial a partir da Declaração Universal dos Direitos do Homem, a questão da fundamentação dos direitos do homem já estaria resolvida, sendo necessário enfocar a questão política da efetivação dos mesmos. Nas palavras do filósofo,

A Declaração Universal dos Direitos do Homem representa a manifestação da única prova através da qual um sistema de valores pode ser considerado

\footnotetext{
${ }^{16}$ BOBBIO, Norberto. A era dos direitos. Trad. Carlos Nelson Coutinho. Rio de Janeiro: Campus, 1992, p. 36

${ }^{17}$ Ibid. p. 38.
} 
humanamente fundado e, portanto, reconhecido: e essa prova é o consenso geral acerca da sua validade. ${ }^{18}$

Ante o exposto, percebe-se que Bobbio não propriamente nega a existência de um fundamento para os direitos do homem. Contudo, seu pensamento foi situado dentro das teorias negativistas, já que não reconhece importância à discussão em torno do fundamento por considerar resolvida a questão pela obtenção do consenso geral.

Tal construção teórica nos parece criticável. Primeiramente, a idéia de acordo geral sobre os valores como fundamento dos direitos humanos se revela perigosa, haja vista as tragédias que o consenso já respaldou. A título exemplificativo, vale lembrar que o holocausto foi levado a cabo pela Alemanha Nazista dentro do aparato da legalidade formal e com o apoio da grande maioria da população do Estado, sob o argumento romantista de purificação da raça ariana.

Por conseguinte, a questão da fundamentação dos direitos humanos mostra-se de enorme importância. Não se afigura adequado relegá-la à pura discricionariedade da intersubjetividade dos homens, sem que se reconheça como pré-estabelecido um mínimo ético a ser respeitado.

Aponte-se, ainda, como crítica, que Bobbio, ao pretender direcionar toda a discussão para o plano pragmático da eficácia dos direitos humanos, parte de uma premissa que também pode ser considerada ilusória, a saber, o consenso geral. Nesse sentido, segundo Perez Luño, "cabe objetar a este planteamiento optimista que la constante violación actual de los derechos humanos muestra la falta de arraigo y la precariedad de esas pretendidas «convicciones generalmente compartidas»" ${ }^{\prime 19}$.

\subsubsection{Perspectiva positivista}

Por seu turno, a perspectiva positivista não confere relevo à discussão sobre os fundamentos dos direitos do homem por reputar ser esta uma questão insolúvel e, por consequência, inútil. Não estando os valores sujeitos à demonstração científica através do método empírico, eles não seriam cognoscíveis pelo homem. Desse modo, restaria infrutífera qualquer tentativa de fundamentação racional dos direitos humanos.

\footnotetext{
${ }^{18}$ Ibid. p. 46.

${ }^{19}$ PEREZ LUÑO, Antonio-Enrique. La fundamentación de los derechos humanos. Revista de Estudios Políticos (Nueva Epoca), no 35, septiembre-octubre, 1983, p. 8
} 
Como vertente do não-cognitivismo, o neopositivismo, que tem como principais expoentes Rudolf Carnap, Alfred Ayer e Stevenson, deu origem ao emotivismo axiológico. De acordo com esse pensamento, os enunciados éticos ostentariam uma função emotiva, correspondente aos sentimentos morais.

Ainda no sentido do não-cognitivismo, é válido assinalar a obra de Enrique Haba. Segundo esse autor, tanto sob o prisma teórico, quanto sob o empírico ou o metafísico, a discussão acerca da justificação dos diretos humanos careceria de qualquer importância prática $^{20}$.

Assentadas as bases da perspectiva não-cognoscitivista, notadamente positivista, é possível argumentar que ela se mostra equivocada, pois parte de uma premissa reducionista ao conceber a realidade apenas como o mundo do ser. Entretanto, conforme expõe a fenomenologia, a realidade é constituída tanto pelo domínio dos seres naturais, quanto pelo dos seres ideais, não sendo admissível ignorar a existência da atividade espiritual. Nesse contexto, Aquiles Guimarães constata que:

\begin{abstract}
A técnica vem corroendo progressivamente todos os laços que projetavam o homem ao universo das suas relações com a transcendência, com aquilo que sempre esteve fora do alcance da razão, mas que se constituía em fonte da imaginação teológica, metafísica, artística e científica. ${ }^{21}$
\end{abstract}

Por conseguinte, conclui-se que o argumento positivista da não demonstrabilidade científica dos valores não tem o condão de retirar a importância da questão da fundamentação dos direitos humanos. Conforme demonstrado, é necessário atentar não somente para a atividade intelectiva do ser humano, mas também para a sua condição de valor-fonte de todos os valores, o que remete, segundo Reale, à esfera do dever-ser.

\title{
3.1.3. Análise das teorias negativistas
}

As teorias negativistas, ao recusarem relevância à discussão sobre a justificação dos direitos do homem, não nos parecem defensáveis. A investigação sobre a temática do fundamento é dotada de insubstituível importância a fim de que possa ser evidenciada a essência do ser. Nesse ínterim, impende transcrever as elucidativas lições sobre fundamento do professor Jorge Câmara:

\footnotetext{
${ }^{20}$ HABA, Enrique P. El asunto del <<fundamento〉> para los derechos humanos: ipseudoproblema! (O bien, cuestión de unas elucidaciones cuasiteológicas). DOXA, Cuadernos de Filosofía del Derecho, 27, 2004, p. 429435.

${ }^{21}$ GUIMARÃES, Aquiles Côrtes. Direito, valor e técnica. Cadernos da EMARF, Fenomenologia e Direito. Rio de Janeiro, v. 1, nº 2, out.2008/mar.2009, p. 96.
} 
a fundamentação do existir, enquanto questão eminentemente ontológica na sua relação com o ser e nas consequiências do existir, estabelece as premissas de análise de qualquer variação que o fenômeno possa apresentar. Com isso a questão sobre a continuidade do ente em suas metamorfoses contextuais é questão intrinsicamente vinculada a delimitação do fundamento do fenômeno. ${ }^{22}$

Verifica-se que, sob a perspectiva realista, a discussão acerca do fundamento perde importância com base na adoção de um relativismo histórico. Por sua vez, a ótica positivista se fulcra na desconsideração das questões axiológicas em razão de não serem apreensíveis empiricamente.

Contudo, quando se prescinde da questão do fundamento, tem-se como consequência a inviabilidade do controle de legitimidade das manifestações do fenômeno em virtude do desconhecimento da sua significação. Esse ambiente representa, então, um terreno fértil para o desenvolvimento das mais horrendas tragédias. Conforme ilustra Comparato,

\begin{abstract}
na ausência de uma razão justificativa exterior e superior ao sistema jurídico, um regime de terror, imposto por autoridades estatais investidas segundo as regras constitucionais vigentes, e que exercem seus poderes dentro da esfera formal de sua competência, não encontra outra razão justificativa ética, senão a sua própria subsistência. $^{23}$
\end{abstract}

É indiscutível a necessidade de se buscarem meios efetivos de garantia dos direitos da pessoa humana. Todavia, essa importante questão política não elide a pertinência do escopo filosófico de se perquirirem os valores que fundam os direitos humanos.

Destarte, a seguir, serão abordadas, de modo sucinto, as principais construções teóricas que enfrentam a referida questão. Essas teorias, aqui denominadas genericamente de fundamentadoras, intentam justificar os direitos humanos com base em distintos pilares, classificados em subjetivistas, intersubjetivistas e objetivistas.

\title{
3.2 Teorias fundamentadoras
}

\subsubsection{Subjetivismo}

Os doutrinadores que fundamentam os direitos humanos sob uma perspectiva subjetiva asseveram que os valores devem ser apreendidos por cada pessoa, com base nos seus

\footnotetext{
${ }^{22}$ CÂMARA, Jorge Luis Fortes Pinheiro da. Os fundamentos e a crise do direito na modernidade: perspectivas filosóficas dos direitos humanos segundo a fenomenologia. Tese de doutorado em Filosofia na UFRJ, Instituto de Filosofia e Ciências Sociais. Rio de Janeiro, 2007, p. 20.

${ }^{23}$ COMPARATO, Fábio Konder. Fundamento dos Direitos Humanos. Instituto de Estudos Avançados da Universidade de São Paulo, p. 8. Disponível em: < http://www.buscalegis.ufsc.br/revistas/index.php/buscalegis/article/viewFile/33031/32211> Acesso em 15/10/10.
} 
interesses individuais. Tais valores éticos particulares, por sua vez, deveriam ser respeitados de modo absoluto pelos demais sujeitos. Portanto, constata-se que esse pensamento parte de um subjetivismo axiológico.

Consoante expõe Perez Luño, as teorias fundamentadoras subjetivas podem ser interpretadas à vista do primado da liberdade individual ou de uma releitura do jusnaturalismo ${ }^{24}$. No primeiro caso, apontam-se como principais expoentes os neoliberais Friedrich von Hayek e Karl Popper. Por seu turno, sob a segunda perspectiva, encontramos os pensadores John Rawls, Ronald Dworkin e Robert Nozick.

A principal crítica tecida a essas construções teóricas está relacionada aos perigos da exacerbação do individualismo, de modo a se prescindirem valores sociais básicos ${ }^{25}$. Além disso, receia-se o distanciamento das necessidades do ser humano, porquanto, consoante explica Perez Luño, "las tesis neoliberalis e neocontractualistas, aunque se presentan como fundamentaciones subjetivas de los derechos humanos al concebirlos como categorías al servicio de la individualidad, terminan por ignorar las exigencias concretas de los individuos por carecer de una adecuada justificación antropológica de sus presupuestos"26.

\subsubsection{Intersubjetivismo}

A ótica intersubjetiva, por sua vez, embora também enfoque a pessoa na tarefa de identificação dos valores, busca alcançar certa objetividade por meio do consenso, trabalhando com a noção de valores comunicáveis intrinsecamente. Tal concordância geral seria obtida a partir das necessidades compartilhadas pelos indivíduos.

Nesse contexto, se inserem as idéias de Jürgen Habermas. De acordo com o filósofo alemão, a ação comunicativa permitiria alcançar a correição ou não de um argumento quando obtido o consenso.

Outrossim, aponte-se a Escola de Budapeste, a qual efetuou uma reformulação da definição marxista de necessidade. Dessa forma, ela erigiu as necessidades radicais, determinadas pela concordância geral, como categorias valorativas.

\footnotetext{
${ }^{24}$ PEREZ LUÑO, Antonio-Enrique. La fundamentación de los derechos humanos. Revista de Estudios Políticos (Nueva Epoca), n ${ }^{\circ} 35$, septiembre-octubre, 1983, p. 23-44.

${ }^{25} \mathrm{H}$. Hart, Entre el principio de utilidad y los derechos humanos, trad. cast. de Ma . D. González, F. Laporta y L. Hierro, en RFDUC, 1980, núm. 58, págs. 7 y siguientes esp., págs. 26 sigs., apud PEREZ LUÑO, AntonioEnrique. Op. cit. p. 43.

${ }^{26}$ PEREZ LUÑO, Antonio-Enrique. Op. cit. p. 43-44.
} 
Em síntese, de acordo com a perspectiva intersubjetiva, os valores apreendidos através do consenso e correspondentes às necessidades radicais dos homens teriam validade universal, fundamentando os direitos humanos. A respeito da temática, é interessante destacar a seguinte observação de Perez Luño:

\begin{abstract}
Entiendo que la fundamentaeión intersubjetivista del valor de Habermas y Apel, de un lado, y las tesis sobre el particular de la Escuela de Budapest, de otro, no sólo son compatibles, sino que se complementan. La primera tiene su aspecto más sólido en la construcción del marco formal para una teoría consensual del valor, pero no profundiza adecuadamente en los datos antropológicos - las necesidades - que constituyen el substrato del consenso; mientras que la segunda ha analizado con mayor precisión estos datos, pero ha debilitado los presupuestos formales para su universalización. ${ }^{27}$
\end{abstract}

Insta notar, ainda, que optamos por abordar o posicionamento de Noberto Bobbio quando da exposição das teorias negativistas, visto que o filósofo reputa desnecessária a discussão sobre o fundamento dos direitos do homem. Assim, ainda que partilhe da visão da intersubjetividade ao empregar a noção de consenso valorativo geral, ele considera já resolvida a questão da fundamentação dos direitos humanos à vista da Declaração Universal dos Direitos do Homem.

\title{
3.2.3 Objetivismo
}

Enfim, dentre as teorias que visam justificar objetivamente os direitos humanos, destaca-se a ética material dos valores, a qual se baseia na visão universalista da axiologia, já aludida no capítulo anterior. Para essa corrente, as invariantes axiológicas, caracterizadas pela universalidade, atemporalidade e pré-existência, fundamentariam os direitos humanos. Por outro lado, considerando que o homem, na condição de valor-fonte de todos os valores, os assimilaria pela intuição emocional, conclui-se que o fundamento do fundamento consiste na própria consciência do homem.

Conforme já evidenciado, a questão do fundamento é de crucial importância, pois permite a captação da essência do ser. Porém, mais do que isso, se afigura necessária a identificação de fundamentos absolutos, vez que o relativismo se aproxima da própria negação do fundamento ao desconsiderar que este possua um conteúdo pré-estabelecido.

Tendo em vista a exposição das principais teorias fundamentadoras no presente capítulo, é possível afirmar que tanto a perspectiva subjetivista, quanto a intersujetivista, recaem em última análise, num relativismo axiológico, pois subordinam o conteúdo dos

\footnotetext{
${ }^{27}$ Ibid. p. 56.
} 
valores à definição do homem. Por seu turno, a ótica objetivista propugna que os valores préexistem, sendo, tão-somente, captados pela consciência intencional doadora de sentidos do homem, o que consubstancia um universalismo axiológico.

Saliente-se que tal distinção não se cinge a um mero "jogo de palavras". Ao revés, a questão da pré-existência dos valores implicará no reconhecimento ou não da limitação do homem a determinado mínimo ético. Com efeito, sob os vieses subjetivista e intersubjetivista, é o homem quem estabelece o valores a serem por ele respeitados, seja de modo atomizado ou por meio do consenso geral. Por sua vez, para a visão objetivista, o homem está sujeito à observância de determinados valores absolutos e universais existentes no domínio dos seres ideais.

O fato de que inexiste consenso entre os próprios universalistas acerca de quais sejam esses valores que compõem a invariância axiológica não possui o condão de refutar a construção teórica em tela. Na verdade, tal crítica se direciona ao plano da eficácia, e não da validade da teoria, vez que não atinge as premissas em que a mesma se baseia.

A respeito da questão, entendemos que os processos históricos pelos quais passa o homem lhe permitem, paulatinamente, obter um maior esclarecimento sobre o conteúdo das invariantes axiológicas. Ou seja, as experiências históricas da humanidade conferem subsídios para uma melhor intuição dos valores pela consciência. Dessa forma, ainda que os valores universais e absolutos não estejam intuídos na sua totalidade, tal difícil tarefa deve ser constantemente buscada, sob pena se desconsiderar qualquer limitação ética às condutas do ser humano. Pelo exposto, o estudo do fundamento nunca restará destituído de importância.

Ainda no que toca ao historicismo, cabe destacar as elucidativas lições de Aquiles Guimarães:

\begin{abstract}
é necessário deixar claro que a existência de um reino autônomo de valores, onde estão situados os valores vitais, espirituais e religiosos, não implica a exclusão de um certo relativismo crítico, tendo em vista a diversidade das culturas e a emergência de novos direitos que configuram a percepção de novos valores que devem ser protegidos no curso da existência histórica do homem. Esse relativismo crítico diz respeito à adaptação dos valores aos novos direitos e às mutações da história e não à relativização das referências universais e imutáveis constantes das potencialidades intencionais da estrutura do espírito humano. Os valores, como seres ideais a priori, antecedem todas as mutações da existência humana enquanto referências supremas da articulação da vivência histórica. ${ }^{28}$
\end{abstract}

Nesse contexto de fundamentação dos direitos humanos com base em valores absolutos, cabe analisar uma questão muito discutida atualmente a título ilustrativo. É notório

\footnotetext{
${ }^{28}$ GUIMARÃES, Aquiles Côrtes. Direito, valor e técnica. Cadernos da EMARF, Fenomenologia e Direito. Rio de Janeiro, v. 1, n 2, out.2008/mar.2009, p. 98.
} 
que alguns doutrinadores têm sustentado a legalização do aborto com fulcro em um dado pragmático, qual seja, o número de mulheres que morrem todos os dias em função de abortos realizados de modo irregular. Tal argumentação, todavia, nos afigura descabida, uma vez que não enfrenta o fundamento da questão.

Considerando que o homem é o valor-fonte de todos os valores e que a vida constitui a condição de existência do homem no mundo, intui-se que a vida consubstancia o valor maior. Desse modo, um argumento meramente pragmático não teria o condão de se sobrepor ao fundamento correspondente ao valor vida para se admitir a legalização do aborto, sob pena de retornarmos ao perigoso terreno do relativismo e ao aforismo de que os fins justificam os meios. Diante disso, conclui-se que o único ponto passível de discussão para a solução dessa tormentosa questão seria o referente ao momento em que a vida tem início, que nos parece corresponder à fecundação em razão do desenvolvimento natural da pessoa humana a partir daí.

Ante todo o exposto, constata-se a importância da visão universalista da axiologia para a fundamentação dos direitos humanos. Como ressalva, não foram analisados os possíveis critérios para a apreensão desse núcleo absoluto dos valores por escapar à temática proposta para o presente artigo.

\section{CONCLUSÃO}

O presente artigo buscou abordar a questão da fundamentação dos direitos humanos, especificamente sob o prisma axiológico. Consoante restou evidenciado, a orientação adotada na seara da teoria dos valores - relativismo ou universalismo - possui implicação direta no modo de compreensão dos fundamentos dos direitos do homem e no grau de importância conferida ao assunto.

À vista de todo o exposto no bojo do trabalho, concluímos que, não obstante a conjuntura efêmera característica da sociedade contemporânea, se afigura inadmissível a conformação com um relativismo histórico, o qual recusa a existência de valores absolutos e universais. Tal posicionamento, em última análise, se aproxima da própria negativa de existência ao fundamento por destituí-lo do seu conteúdo material.

Reitere-se que referida conclusão não importa na rejeição de um relativismo crítico. Conforme anotado, o homem é um ser essencialmente histórico e os fenômenos reais são mutáveis. Entendemos, contudo, que, a despeito disso, os valores subsistem na qualidade de 
objetos ideais pré-existentes, eis que, entre os seres reais e os ideais há apenas uma relação de referibilidade. Tal orientação corresponde ao historicismo axiológico de Miguel Reale.

Por conseguinte, com base na visão universalista dos valores, compreendemos que os direitos humanos possuem um fundamento absoluto, conferido a partir da idéia de invariantes axiológicas apreensíveis pela intuição emocional. Dessa maneira, o seu fundamento último é a consciência humana doadora de sentidos ao mundo.

\section{REFERÊECIAS:}

ARENDT, Hanna. Sobre a violência. Tradução de André Duarte. $3^{\text {a }}$ ed. Rio de Janeiro: Relume Dumará, 2001, p. 13-30.

AYDIN, Ciano. Além do Absolutismo e do Relativismo: Nietzsche e Peirce. Tradução por Clayton Foschiani de Conferência realizada no $8^{\circ}$ Encontro Internacional sobre Pragmatismo. Centro de Estudos do Pragmatismo - Pontifícia Universidade Católica de São Paulo.

BOBBIO, Norberto. A era dos direitos. Trad. Carlos Nelson Coutinho. Rio de Janeiro: Campus, 1992, p. 35-65.

CADENA, Nathalie Barbosa de la. Fundamentos metafísicos para a universalização dos Direitos Humanos. Revista Ítaca, ${ }^{\circ}$ 9, 2008, p. 141-150.

CÂMARA, Jorge Luis Fortes Pinheiro da. Os fundamentos e a crise do direito na modernidade: perspectivas filosóficas dos direitos humanos segundo a fenomenologia. Tese de doutorado em Filosofia na UFRJ, Instituto de Filosofia e Ciências Sociais. Rio de Janeiro, 2007.

COMPARATO, Fábio Konder. Fundamento dos Direitos Humanos. Instituto de Estudos Avançados da Universidade de São Paulo. Disponível em: < http://www.buscalegis.ufsc.br/revistas/index.php/buscalegis/article/viewFile/33031/32211> Acesso em 15/10/10.

DA SILVA, Fernanda Duarte Lopes Lucas. Fundamentando os Direitos Humanos: Um Breve Inventário. In: TORRES, Ricardo Lobo (Org.). Legitimação dos Direitos Humanos. Rio de Janeiro: Renovar, 2002, p. 99-137.

GUIMARÃES, Aquiles Côrtes. Direito, valor e técnica. Cadernos da EMARF, Fenomenologia e Direito. Rio de Janeiro, v. 1, n 2, out.2008/mar.2009, p. 87-98. 
. Edmundo Russerl e o Fundamento Fenomenológico do Direito. Cadernos da

EMARF, Fenomenologia e Direito. Rio de Janeiro, v. 2, nº 1, abr./set.2009, p. 67-79.

. O que é a teoria tridimensional do Direito? Estudos Jurídicos, p. 4-5.

. Para uma teoria fenomenológica do Direito - I. Cadernos da EMARF,

Fenomenologia e Direito. Rio de Janeiro, v. 3, n 1, abr./set.2010, p. 15-26.

HAARSCHER, Guy. Filosofia dos Direitos do Homem. Trad. Armando Pereira da Silva. Lisboa: Instituto Piaget, 1997, p. 41-55.

HABA, Enrique P. El asunto del <<fundamento〉> para los derechos humanos: ¡pseudoproblema! (O bien, cuestión de unas elucidaciones cuasiteológicas). DOXA, Cuadernos de Filosofía del Derecho, 27, 2004, p. 429-435.

HEIDEGGER, Martin. A essência do fundamento. Lisboa: Edições 70, p. 14-33.

HUSSERL, Edmund. A idéia da fenomenologia. Lisboa: Edições 70, 2008, p. 39-49.

JAIME, Jorge. Ser e Valor. Vol. 1, 2a ed. Rio de Janeiro, 2003, p. 45-74.

PEQUENO, Marconi. O fundamento dos direitos humanos. Educação em Direitos Humanos: fundamentos histórico-filosóficos. Disponível em: < http://www.dhnet.org.br/dados/cursos/edh/redh/01/02_marconi_pequeno_fundamento_dh.pdf $>$ Acesso em 15/10/10.

PEREZ LUÑO, Antonio-Enrique. La fundamentación de los derechos humanos. Revista de Estudios Políticos (Nueva Epoca), no 35, septiembre-octubre, 1983, p. 7-71.

REALE, Miguel. Paradigmas da cultura contemporânea. $1^{\text {a }}$ ed. $2^{\text {a }}$ tir. São Paulo: Saraiva, 1999.

ROCHA, Silvia Pimenta Velloso. O relativismo como niilismo, ou os sem teto da metafísica. Revista Trágica: estudos sobre Nietzsche, $2^{\circ}$ semestre de 2008, vol. 1, nº 2, p. 161-169.

TERRA, Ricardo. Kant \& o direito. Rio de Janeiro: Jorge Zahar Editor, 2004. 